\title{
PERANCANGAN APLIKASI VOICE OF INSOMNIA DENGAN ALGORITMA SEQUENCIAL BERBASIS ANDROID
}

\author{
${ }^{1)}$ Fitri L Rais, M.Kom, ${ }^{2)}$ Bahtiar Khaelani \\ Komputerisasi Akuntansi, AMIK BSI Jakarta, Teknik Informatika, STMIK Nusa Mandiri, \\ 1) bahtiar.khaelani@gmail.com, ${ }^{2)}$ fitri.latifah@bsi.ac.id
}

\begin{abstract}
Abstrak
Perkembangan teknologi informasi membuat berbagai aktivitas dalam kehidupan manusia mengalami evolusi. Berbagai aktivitas mengalami perubahan dari cara konvensional yang secara praktiknya manual menjadi cara modern yang umumnya sudah berbentuk digital (menggunakan komputer). Masyarakat memilih untuk menggunakan cara modern karena menawarkan kecepatan, otomatisasi dan kemudahan dalam melakukan berbagai kegiatan sehari-hari, hal tersebut menyebabkan dituntut adanya teknologi dan perangkat elektronik yang lebih mudah dan bermanfaat dalam penggunaannya. Berbagai macam terapi didunia ini yang menggunakan musik atau suara alam sebagai perantaranya, musik relaksasi tersebut didengarkan melalui perangkat-perangkat elektronik baik pemutar MP3 Player, Radio dan perangkat android. Aplikasi berbasis android Voice OF Insomnia yaitu sebuah aplikasi android terapi musik relaksasi bagi para pengidap gangguan tidur atau insomnia.
\end{abstract}

\begin{abstract}
The development of information technology makes the various activities in human life undergoing evolution. Various activities have changed from the conventional way which is practically manual into modern way which generally have been digital (using computer). People choose to use the modern way because it offers speed, automation and ease in performing various daily activities, causing the demanded of technology and electronic devices that are easier and useful in its use. Various kinds of therapies in this world that use music or natural sounds as a mediator, relaxation music is heard through electronic devices both MP3 Player, Radio and android devices. Android-based applications Voice OF Insomnia is an application android music relaxation therapy for people with sleep disorders or insomnia.
\end{abstract}

Key Word: Insomnia, Musik Therapy, Android Application

\section{Pendahuluan.}

Perkembangan teknologi informasi membuat berbagai aktivitas dalam kehidupan manusia mengalami evolusi. Berbagai aktivitas mengalami perubahan dari cara konvensional yang secara praktiknya manual menjadi cara modern yang umumnya sudah berbentuk digital (menggunakan komputer). Masyarakat memilih untuk menggunakan cara modern karena menawarkan kecepatan, otomatisasi dan kemudahan dalam melakukan berbagai kegiatan sehari-hari, hal tersebut menyebabkan dituntut adanya teknologi dan perangkat elektronik yang lebih mudah dan bermanfaat dalam penggunaannya Teknologi yang sedang mendapatkan banyak perhatian dari masyarakat adalah android. Android merupakan sebuah operation system yang mendukung era "open-source" dan menjanjikan kemudahan bagi pengguna mendapatkan aplikasi juga pihak pengembang software untuk mengembangkan aplikasi. Contoh penggunaa Android untuk kegiatan 
sehari-hari, ketika seseorang ingin membaca buku, dia tidak perlu membawa buku tersebut, cukup menggunakan $e$ book reader.

Penggunaannya smartphone berbasis android semakin berkembang hingga menyentuh bidang bisnis, contohnya yaitu seorang sales perusahaan yang menawarkan produk ke toko menggunakan tablet berbasis android untuk menampilkan bentuk fisik, informasi serta cara penggunaan dan kinerja produk yang dijual. Proses tersebut mempermudah proses bisnis dan mengubah cara konvensional menjadi lebih mudah dan efisien.

Sebuah masalah klasik tentang gangguan tidur atau insomnia yang kerap diderita oleh seseorang yang biasanya berusia diatas 20 tahun keatas, faktorfaktor penyebab terjadinya insomnia biasanya terjadi karena stress oleh pekerjaan, kurangnya asupan gizi, dan banyak faktor lainnya oleh sebab diperlukan sebuah aplikasi terapi musik untuk mengatasi gangguan tidur atau insomnia.

Aplikasi android terapi musik untuk mengatasi gangguan tidur atau insomnia yang akan dikembangkan oleh penulis ini, yaitu sebuah aplikasi android terapi musik relaksasi untuk mengatasi gangguan susah tidur atau insomnia. Dengan mendengarkan musik relaksasi dari aplikasi android ini diharapkan bisa menjadi sebuah terapi bagi para pengidap gangguan tidur atau insomnia.

Karena Aplikasi ini belum banyak, maka penulis bermaksud melakukan penelitian ini agar bisa mempermudah masyarakat,

\section{Metode Peneltian}

Dalam mengumpulkan data-data guna mendukung penulisan Penelitian ini, maka penulis melakukan penelitian dengan cara sebagai berikut :

\subsection{Teknik Pengumpulan Data}

1. Observasi

Melakukan pengamatan pada masyarakat, aplikasi yang sudah ada dan menjadikannya sebagai contoh.

2. Wawancara

Melakukan beberapa wawancara dengan para responden tentang masalah insomnia atau gangguan tidur lainnya yang meraka alami selama ini dengan maksud untuk mendapatkan sumber bahan-bahan langsung.

3. Studi Pustaka

Untuk menambah materi dari penelitian maka penulis mencoba melakukan studi kepustakaan yaitu dengan mengumpulkan data-data teoritis dan mempelajari buku-buku atau literatur dengan maksud untuk mendapatkan teori-teori dan bahanbahan yang berkaitan dengan masalah tersebut diatas.

\subsection{Metode Pengembangan Aplikasi}

\section{Planning}

Perancangan aplikasi dimulai dengan melihat dan mencari apa yang dibutuhkan oleh pengguna dalam mengefektifkan dan mengefesienkan dalam proses pembuatan aplikasi

2. Analisis Kebutuhan

Mengidentifikasi permasalahan yang dihadapi oleh masyarakat dalam mengatasi Insomnia. Menganalisis keandalan dan kelemahan program aplikasi pada teknologi telepon selular yang digunakan.

3. Desain.

Desain software arsitektur merancang bentuk tampilan dengan menggunakan software program Android Studio dengan menggunakan bahasa $x m l$. Desain user interface mengaplikasikan 
rancangan desain program aplikasi antar muka dengan desain use case pada sistem.

\section{Pengkodean.}

Desain harus ditranslasikan kedalam program perangkat lunak. Hasil dari tahap ini adalah program android sesuai dengan desain yang telah dibuat pada tahap desain dengan Bahasa Pemograman Java.

\section{Testing.}

Pengujian fokus pada perangkat lunak secara dari segi logik dan fungsional, memastikan bahwa semua bagian sudah diuji. Hal ini dilakukan untuk meminimalisir kesalahan (error) dan memastikan output yang dihasilkan sesuai dengan yang diinginkan. Pengujian dilakukan untuk mengetahui apakah aplikasi ini bisa berjalan sesuai harapan atau belum.

\section{Hasil dan Pembahasan}

\subsection{Analisa Kebutuhan Software}

Dalam proses pengembangan sebuah aplikasi langkah awal yang perlu dilakukan adalah menganalisa berbagai kebutuhan yang akan dijadikan sebagai masukan atau acuan dalam pembangunan aplikasi tersebut. Kebutuhan tersebut antara lain input yang diperlukan, output yang dihasilkan dan pembuatan design user interface yang mudah digunakan dan mudah dipahami oleh user.

\subsubsection{Identifikasi Masalah}

Dalam proses membangun aplikasi Voice Of Insomnia ini bagaimana kita merancang sebuah aplikasi android yang sederhana serta kita dapat mengimplementasikan aplikasi android ini dan juga sebagai terapi bagi para pengidap gangguan tidur atau insomnia ini. Untuk itu apa yang perlu dilakukan supaya aplikasi android ini dapat diterapkan dan untuk siapa nanti aplikasi android ini dibuat, maka dari itu diperlukan sebuah tinjauan dari beberapa jurnal mengenai insomnia atau gangguan tidur ini, agar pembuatan aplikasi bisa tepat sasaran bagi para penggunanya.

\subsubsection{Analisa Kebutuhan Aplikasi}

Didalam merancang sebuah aplikasi android ini diperlukan sebuah hardware dan software sebagai penunjang dalam penulis membangun sebuah aplikasi android, oleh sebab itu bagaimana kebutuhan Software dan hardware yang diperlukan agar aplikasi android ini dapat dibangun dan diterapkan baik itu di mobile devices ataupun di mesin. Selanjutnya kebutuhan untuk menyelesaikan permasalahan yang ditemukan sebagi berikut :

1. Spesifikasi Perangkat Lunak

Penulis menggunakan sistem operasi windows 8 dan dalam pembuatan aplikasi menggunakan software Android Studio. Sedangkan untuk implementasinya penulis menggunakan Emulator dan perangkat smartphone yang berbasis android.

\section{Spesifikasi Komputer}

Untuk membuat dan mengembangkan aplikasi yang akan dibuat dibutuhkan spesifikasi computer hardware dan software sebagai berikut :
a. Processor Intel Core i5-3230 (2,6Ghz)

b. RAM 4GB DDR3

c. Graphic NVIDIA GeForce

d. Hardisk 320GB

e. Layar 14 Inches

f. Android Studio 3.1

g. Android SDK Tools

h. Android Development Tools

i. Intel® VT-x, Intel ${ }^{\circledR}$ EM64T (Intel® 64), and Execute Disable (XD) Bit functionality 


\subsection{Desain}

\subsubsection{Rancangan Algoritma}

Rancangan Algoritma Sekuensial pada aplikasi Voice Of Insomnia untuk memutar suara dari zebra finch bird

1. Inisialisasi button relaxing sound di main activity

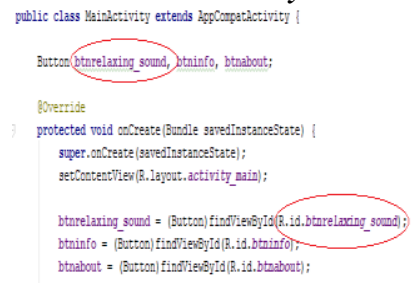

Gambar 1 Inisialisasi Button Relaxing Sound

2. Setting untuk membuka jendela activity relaxing sound class

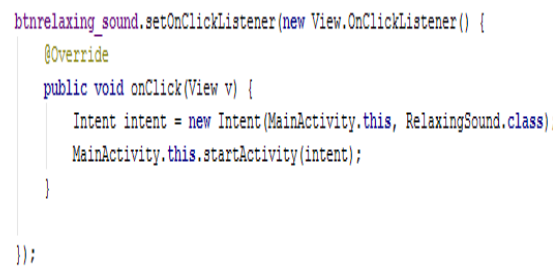

Gambar 2 Setting Button Relaxing Sound

3. Inisialisasi button zebra finch bird di activity relaxing sound untuk membuka jendela activity zebra finch class

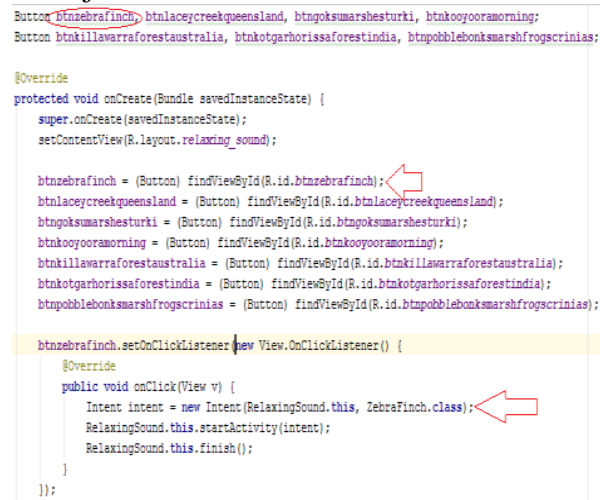

Gambar 3 Inisialisasi Button Zebra Finch Bird

4. Inisialialisasi butoon play, pause, dan stop untuk memutar suara zebra finch bird. public class Zebrarinch extends AppcompatActivity

implements MediaPlayer. OnCorpletionIistener

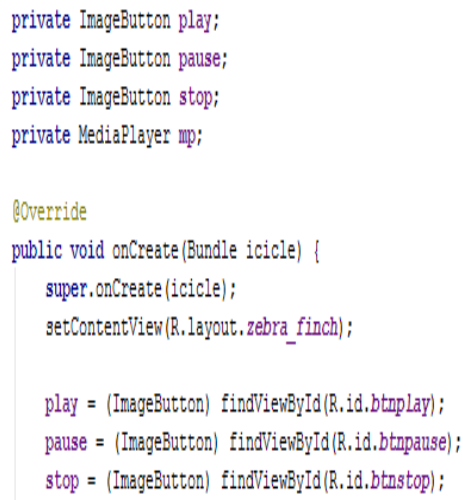

Gambar 4 Inisialisasi Button Play, Pause, dan Stop

5. Setting untuk memutar suara dari

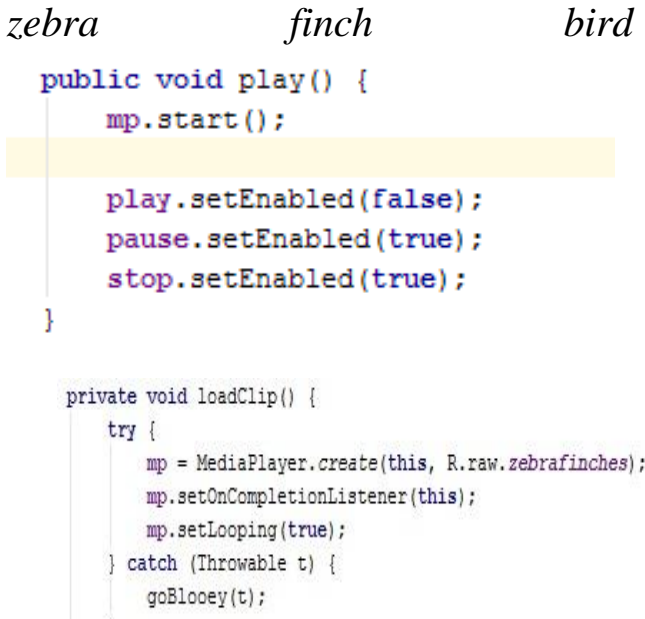

Gambar 5 Setting untuk Memutar Suara Zebra Finch Bird

Keterangan :

Jika kita menekan button play setelah itu button play akan bernilai false, dan button pause dan stop akan bernilai true, dan akan membuka file suara zebrafinches dari folder raw.

\subsubsection{Software Architecture}

Rekayasa perangkat Lunak merupakan bagian dari system yang meliputi pembangunan perangkat lunak, infrastruktur, control, aplikasi, dan database pada system dengan tujuan menghasilkan perangkat lunak yang sesuai kebutuhan si pemakai, memiliki 
sifat ekonomis, efisien, mudah dipelajari, mudah perwatannya, dan bertahan lama.

a. Pseudo-code Algoritma

1. Pseudo-code untuk menampilkan tentang menu Info di aplikasi Voice Off Insomnia.

Start

$a=$ "info"

print a

end

2. Pseudo-code untuk menampilkan tentang menu About di aplikasi Voice Of Insomnia.

Start

$\mathrm{b}=$ "about"

print $b$

end

b. UML

(Unified

Modeling

Language).

1. Diagram Use Case

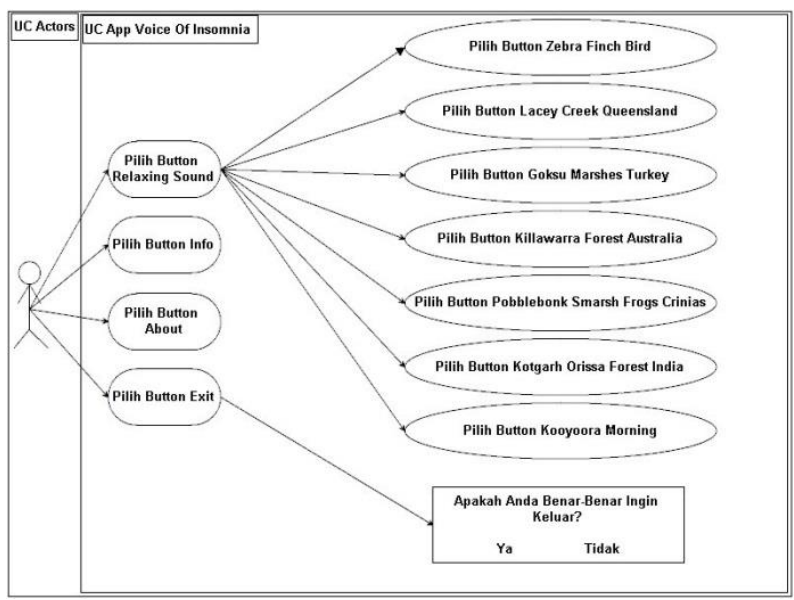

Gambar 6 Diagram Use Case Voice Of Insomnia
2. Diagram Activty

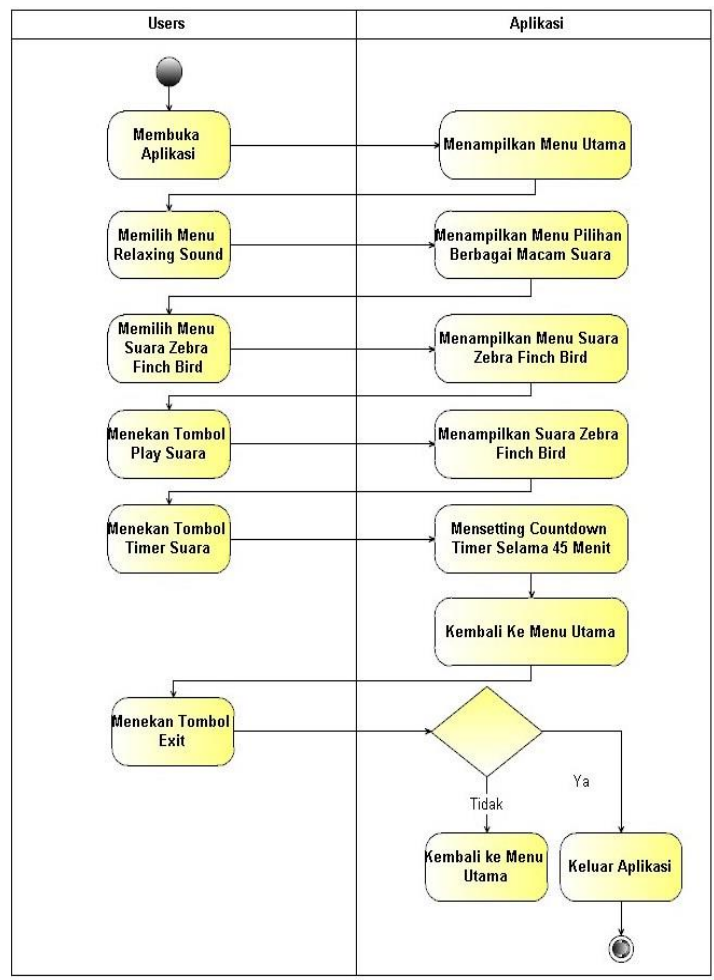

Gambar 7 Diagram Activity Voice Of Insomnia

3. Sequence Diagram

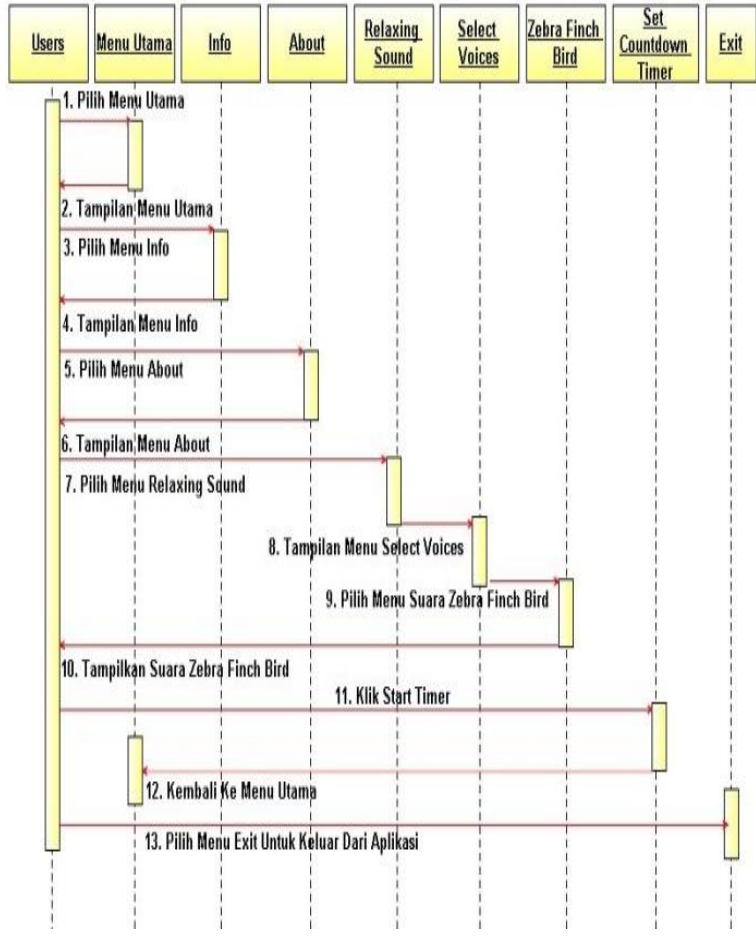

Gambar 8 Diagram Sequence Voice Of Insomnia 


\section{Deployment Diagram}

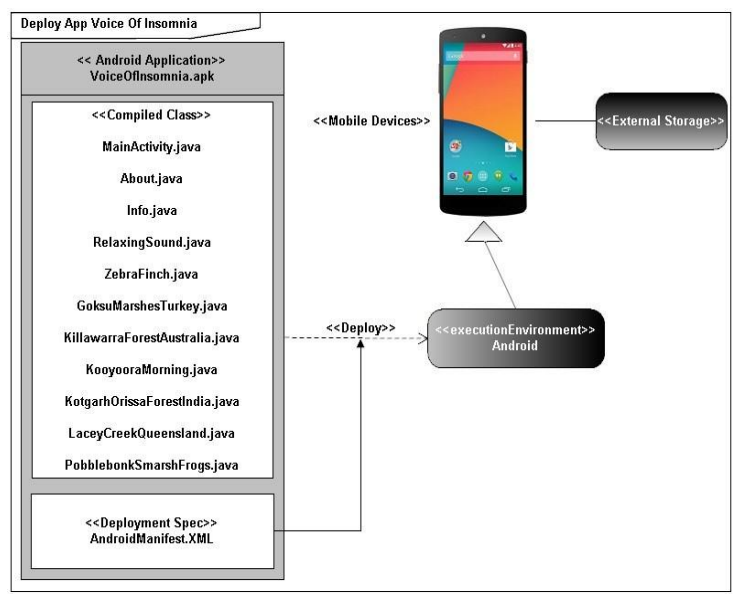

Gambar 9 Diagram Deployment Voice Of Insomnia

\subsection{Implementasi}

Implementasi merupakan salah satu tahap dalam pengembangan sebuah perangkat lunak. Implementasi aplikasi "Voice Of Insomnia" pada aplikasi mobile android menggunakan bahasa pemograman java pada Handphone Xiaomi Redmi 3 dengan OS Android Lollypop.

\section{Tampilan Menu Utama}

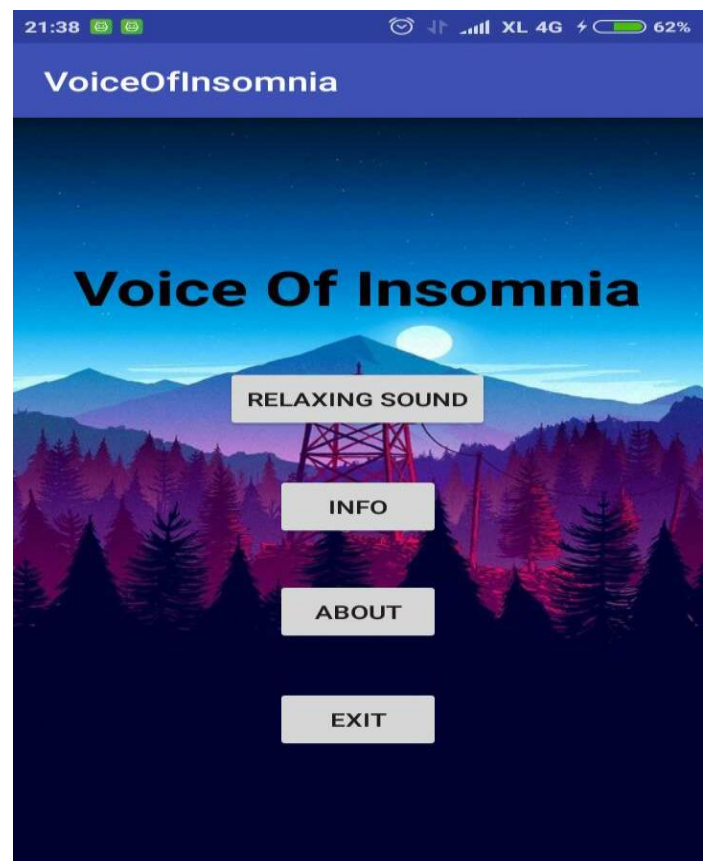

Gambar 10 Tampilan Menu Utama
2. Tampilan Menu Pilihan Suara

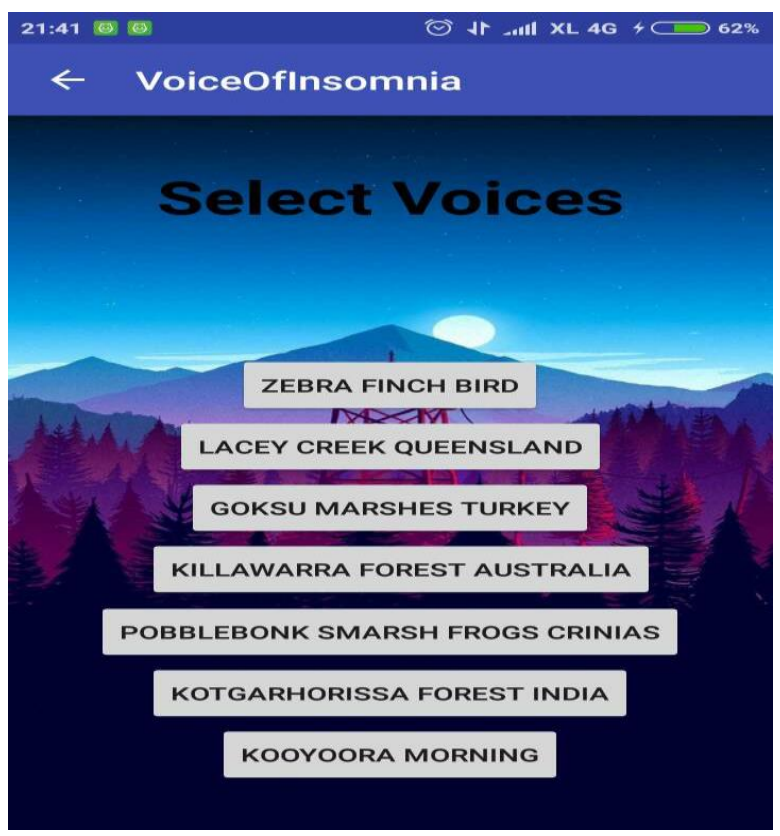

Gambar 11 Tampilan Menu Pilihan Suara

3. Tampilan Menu Info

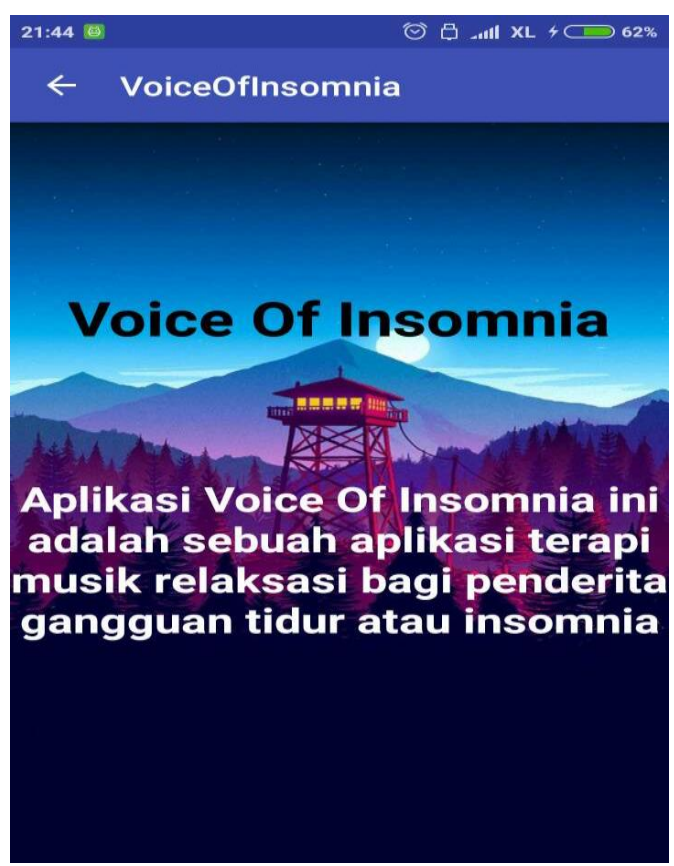

Gambar. 12 Tampilan Menu Info 
4. Tampilan Salah Satu Menu pemutar Suara Voice Of Insomnia

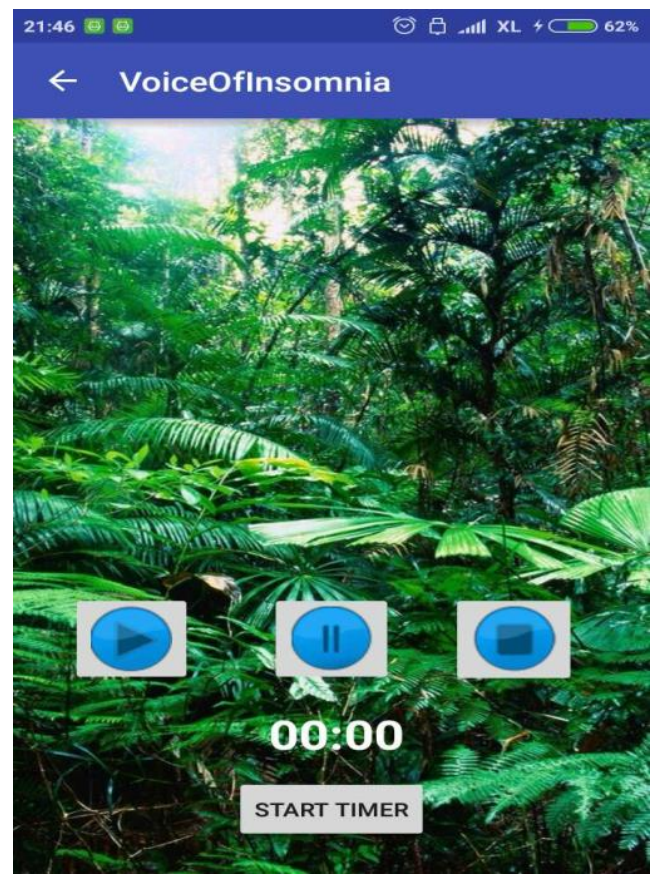

Gambar. 13 Tampilan Salah Satu Menu Pemutar Suara

5. Tampilan Alert Dialog Saat Akan Keluar Aplikasi

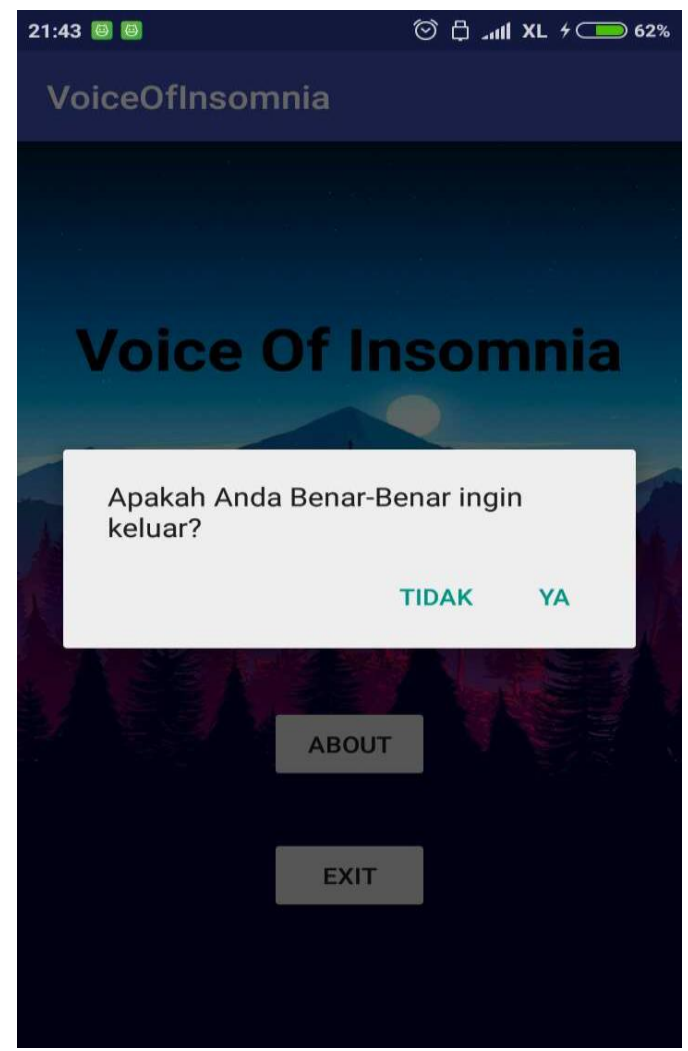

Gambar. 14 Tampilan Alert Dialog Exit

\subsection{Testing}

Mengapa penulis menggunakan teknik blackbox testing dibanding menggunakan whitebox testing dalam menguji aplikasi ini karena diharapkan mampu mengungkap kelas kesalahan yang lebih luas dibandingkan menggunakan teknik whitebox testing. pengujian instalasi aplikasi pada beberapa perangkat serta pengujian fungsionalitas sistem termasuk desain interface. Adapun hasil dari pengujian blackbox testing pada aplikasi ini adalah sebagai berikut:

\section{Tabel III-1 Tabel Blackbox Testing}

\begin{tabular}{|c|c|c|c|c|}
\hline No. & Kelas Uji & Butir Uji & $\begin{array}{c}\text { Jenis } \\
\text { Pengujian }\end{array}$ & $\begin{array}{c}\text { Hasil } \\
\text { Uji }\end{array}$ \\
\hline 1. & Instalasi Aplikasi & $\begin{array}{c}\text { Pemasangan aplikasi pada } \\
\text { beberapa perangkat yang } \\
\text { berbeda }\end{array}$ & Blackbox & Berhasil \\
\hline \multirow{4}{*}{2.} & \multirow{4}{*}{ Main Activity } & Relaxing Sound & Blackbox & Berhasil \\
\hline & & Info & Blackbox & Berhasil \\
\hline & & About & Blackbox & Berhasil \\
\hline & & Exit & Blackbox & Berhasil \\
\hline 3. & Info & $\begin{array}{c}\text { Tampilan tentang info } \\
\text { aplikasi }\end{array}$ & Blackbox & Berhasil \\
\hline 4. & About & $\begin{array}{c}\text { Tampilan tentang pembuat } \\
\text { aplikasi }\end{array}$ & Blackbox & Berhasil \\
\hline 5. & Exit & $\begin{array}{l}\text { Tombol keluar aplikasi } \\
\text { dan muncul Alert Dialog }\end{array}$ & Blackbox & Berhasil \\
\hline \multirow{7}{*}{6.} & \multirow{7}{*}{ Relaxing Sound } & ZebraFinch & Blackbox & Berhasil \\
\hline & & LaceyCreekQueensland & Blackbox & Berhasil \\
\hline & & GoksuMarshesTurkey & Blackbox & Berhasil \\
\hline & & KillawarraF orestAustralia & Blackbox & Berhasil \\
\hline & & PobblebonkSmarshFrogs & Blackbox & Berhasil \\
\hline & & KotgathOrissaForestIndia & Blackbox & Berhasil \\
\hline & & KooyooraMorning & Blackbox & Berhasil \\
\hline \multirow{4}{*}{7.} & \multirow{4}{*}{ ZebraFinch } & Play Button & Blackbox & Berhasil \\
\hline & & Pause Button & Blackbox & Berhasil \\
\hline & & Stop Button & Blackbox & Berhasil \\
\hline & & Start Timer Button & Blackbox & Berhasil \\
\hline
\end{tabular}

\section{Kesimpulan dan Saran}

\subsection{Kesimpulan}

Setelah melalui tahap perancangan, implementasi dan pengujian aplikasi Voice Of Insomnia, maka dapat ditarik kesimpulan bahwa:

1. Aplikasi Voice Of Insomnia yang ditujukan untuk mengatasi gangguan tidur ini dapat berjalan dengan baik dan dapat digunakan untuk terapi bagi para pengidap gangguan susah tidur atau insomnia.

2. Apilkasi ini dibangun untuk memudahkan bagi para pengidap 
gangguan tidur atau insomnia ini sebagai media terapi mobile yang dapat dibawa kemanapun.

Apilkasi Voice Of Imsonia ini dibangun selain sebagai terapi untuk para pengidap insomnia, juga diharapkan untuk mengurangi penggunaan obat-obatan sebagai stimulus oleh para pengidap insomnia.

\subsection{Saran}

Dalam membangun aplikasi Voice Of Insomnia berbasis android ini masih belum sempurna dan masih terdapat banyak kekurangannya. Oleh karena itu perlu di kembangkan dan penyempurnaan lebih lanjut. Adapun saran saran agar aplikasi ini lebih optimal dan lebih menarik adalah sebagai berikut.

1. Untuk selanjutnya diharapkan Aplikasi dapat diimplementasikan pada smart phone android versi yang berbeda.

2. Aplikasi yang dibangun tidak bersifat Client Server. oleh sebab itu untuk selanjutnya dapat dikembangkan dengan Client Server.

3. Untuk selanjutnya diharapkan aplikasi dapat dibangun untuk OS yang berbeda.

Demikian saran yang dapat penulis berikan, semoga saran tersebut bisa dijadikan sebagai bahan masukan yang dapat bermanfaat bagi penulis khususnya dan umumnya bagi masyarakat luas.

\section{Daftar Pustaka}

Ananda, Kun Sila (2014). 5 Manfaat Terapi Musik Untuk Kesehatan. Diambil dari:

https://www.merdeka.com/sehat/5manfaat-terapi-musik-untukkesehatan.html.

Februariyanti, Herny (2011). Pengertian Algoritma, Ciri Algoritma dan Contoh. Diambil dari: http://herny.staff.unisbank.ac.id/2011/ 10/29/pengertian-algoritma-strukturdata-dan-pemrograman/.

Murya, Yosef. (2013). Pemrograman Android Blackbox. Jakarta: Jasakom

Mun, S.H., W. Lim. (2016). Music Player Application with Sleeping Timer for Android Platform. ISSN: 0973-4562. Malacca: Jurnal Ilmiah Kursor Vol. 11, No. 20 Januari 2016: 10178-10182

Mustaqbal, M. Sidi, Roeri Fajri Firdaus, Hendra Rahmadi. (2015). Pengujian Aplikasi Menggunakan Blackbox Testing Boundary Value Analysis (Studi Kasus : Aplikasi Prediksi Kelulusan SNMPTN). ISSN: 24073911. Bandung: Jurnal Ilmiah Kursor Vol. 1, No. 3 Januari 2015: 31-36

Ramadhani, Cipta. (2015). Dasar Algoritma dan Struktur Data dengan Bahasa Java. Yogyakarta: Penerbit Andi

Rizky, Soetomo. (2011). Konsep Dasar Rekayasa Perangkat Lunak. Jakarta: Prestasi Pustaka Publisher

Rudystina, Adinda. (2017). Terapi Musik untuk Kesehatan. Diambil dari: https://hellosehat.com/hidupsehat/fakta-unik/terapi-musik-untukkesehatan/.

Sunaringtyas, Widyasih, Linda Ishariani, Ria Agustin Wahyuningtiyas. (2017). Pengaruh Terapi Musik Suara Air Mengalir dengan Brainwave Terhadap Penurunan Insomnia Pada Lansia di Wilayah Posyandu "Sedap Malam" Pare Kediri. ISSN: 2088-8872. Yogyakarta: Jurnal Ilmiah Kursor Vol. 4, No. 1 Januari 2017: 76-79.

Yates, T. Brian. (2008). Apa Itu Insomnia?. Diambil dari: http://doktersehat.com/apa-ituinsomnia/. 